\title{
The German trial on Aciclovir and Corticosteroids in Herpes-simplex-virus- Encephalitis (GACHE): a multicenter, randomized, double-blind, placebo- controlled trial
}

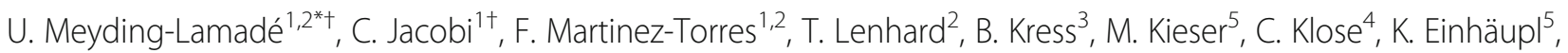 \\ J. Bösel ${ }^{11}$, M-B Mackert ${ }^{6}$, V. Homberg ${ }^{19}$, C. Koennecke' ${ }^{7}$, G. Weißheit ${ }^{7}$, D. Claus ${ }^{8,18}$, B. Kieseier ${ }^{9}$, J. Bardutzky ${ }^{21}$, \\ T. Neumann-Haefelin ${ }^{17}$, M. W. Lorenz ${ }^{1,9}$, H. Steinmetz ${ }^{9}$, C. Gerloff ${ }^{10}$, D. Schneider ${ }^{12}$, A. Grau ${ }^{13}$, M. Klein ${ }^{14}$, \\ R. Dziewas ${ }^{15}$, U. Bogdahn ${ }^{20}$, W. Jakob ${ }^{15}$, R. Linker ${ }^{15}$, K. Fuchs $^{15}$, A. Sander ${ }^{4}$, S. Luntz ${ }^{16}$, T. Hoppe-Tichy ${ }^{20}$, \\ D. F. Hanley ${ }^{23}$, R. von Kummer ${ }^{22}$ and E. Craemer ${ }^{1}$
}

\begin{abstract}
Introduction: Comprehensive treatment of Herpes-simplex-virus-encephalitis (HSVE) remains a major clinical challenge. The current therapy gold standard is aciclovir, a drug that inhibits viral replication. Despite antiviral treatment, mortality remains around $20 \%$ and a majority of survivors suffer from severe disability. Experimental research and recent retrospective clinical observations suggest a favourable therapy response to adjuvant dexamethasone. Currently there is no randomized clinical trial evidence, however, to support the routine use of adjuvant corticosteroid treatment in HSVE.

Methods: The German trial of Aciclovir and Corticosteroids in Herpes-simplex-virus-Encephalitis (GACHE) studied the effect of adjuvant dexamethasone versus placebo on top of standard aciclovir treatment in adult patients aged 18 up to 85 years with proven HSVE in German academic centers of Neurology in a randomized and double blind fashion. The trial was open from November 2007 to December 2012. The initially planned sample size was 372 patients with the option to increase to up to 450 patients after the second interim analysis. The primary endpoint was a binary functional outcome after 6 months assessed using the modified Rankin scale (mRS 0-2 vs. 3-6). Secondary endpoints included mortality after 6 and 12 months, functional outcome after 6 months measured with the Glasgow outcome scale (GOS), functional outcome after 12 months measured with mRS and GOS, quality of life as measured with the EuroQol 5D instrument after 6 and 12 months, neuropsychological testing after 6 months, cranial magnetic resonance imaging findings after 6 months, seizures up to day of discharge or at the latest at day 30 , and after 6 and 12 months.
\end{abstract}

\footnotetext{
* Correspondence: meyding-lamade.uta@khnw.de

†U. Meyding-Lamadé and C. Jacobi contributed equally to this work.

${ }^{1}$ Department of Neurology, Krankenhaus Nordwest, Frankfurt, Germany

${ }^{2}$ Department of Neurology, University of Heidelberg, Heidelberg, Germany

Full list of author information is available at the end of the article
}

(c) The Author(s). 2019 Open Access This article is distributed under the terms of the Creative Commons Attribution 4.0 International License (http://creativecommons.org/licenses/by/4.0/), which permits unrestricted use, distribution, and reproduction in any medium, provided you give appropriate credit to the original author(s) and the source, provide a link to the Creative Commons license, and indicate if changes were made. The Creative Commons Public Domain Dedication waiver (http://creativecommons.org/publicdomain/zero/1.0/) applies to the data made available in this article, unless otherwise stated. 
(Continued from previous page)

Results: The trial was stopped prematurely for slow recruitment after 41 patients had been randomized, 21 of them treated with dexamethasone and 20 with placebo. No difference was observed in the primary endpoint. In the full analysis set ( $n=19$ in each group), 12 patients in each treatment arm achieved a mRS of 0-2. Similarly, we did not observe significant differences in the secondary endpoints (GOS, mRS, quality of life, neuropsychological testing).

Conclusion: GACHE being prematurely terminated demonstrated challenges encountered performing randomized, placebo-controlled trials in rare life threatening neurological diseases. Based upon our trial results the use of adjuvant steroids in addition to antiviral treatment remains experimental and is at the decision of the individual treating physician. Unfortunately, the small number of study participants does not allow firm conclusions.

Trial registration: EudraCT-Nr. 2005-003201-81.

\section{Introduction}

Herpes-simplex-virus-encephalitis (HSVE) is the most common cause of sporadic encephalitis in humans. Worldwide HSVE accounts for $5-10 \%$ of all cases of encephalitis. The annual incidence is reported to be between 2 and 4 cases/1,000,000 at any age. Mortality is around $70 \%$ and disability is highly prevalent in untreated patients. Poor outcome is more likely with an initial severe course of the encephalitis such as a Glasgow coma scale score (GCS) less than 6 and symptoms already present for more than 4 days [1-3].

Aciclovir is the current standard antiviral therapy for HSVE. In the mid-1980s two large randomized clinical trials showed that the use of intravenous aciclovir reduced the 6 -month mortality rate by about $20 \%$ and significantly decreased morbidity. However, almost $2 / 3$ rds of the survivors display residual neurologic deficits. Even after early antiviral treatment, less than $20 \%$ of patients are able to go back to work and the majority of patients suffer from severe disability [1, 2, 4, 5].

Secondary mechanisms of injury beyond the direct virus-mediated tissue damage have been discussed to play a significant role in the pathogenesis of HSVE. On magnetic resonance imaging (MRI) HSVE patients may show late chronic progressive tissue damage despite early treatment with acyclovir [6]. The mechanisms underlying this virus-independent structural damage are believed to be autoimmune in nature $[1,7]$. In experimental HSVE, the expression of immunologic Nitric oxid synthase, matrix metalloproteinases and chemokines has been described in the brain and hypothesized to be involved as a secondary mechanism [8-10]. Initial viral load does not correlate with the extent of cranial MRI abnormalities in patients with HSVE [11]. Experimental models of HSVE have shown that viral load is not influenced by treatment with corticosteroids and that the corticosteroids have no adverse effect on the encephalitic process. In a mouse model of HSVE the combination of aciclovir together with steroids has reduced progressive MRI changes compared to aciclovir treatment alone [7, 12, 13].

In humans, steroid treatment of HSVE was used before aciclovir was developed and beneficial effects were described $[14,15]$. The only evidence on the adjuvant treatment with steroids in HSVE has been published in case reports or in a retrospective clinical study [2, 16-18]. The non-randomized retrospective study included 45 patients with HSVE. A poorer outcome was present in patients without corticosteroid treatment [17]. Thus far, no prospective or randomized trial evidence is available on the adjuvant treatment with steroids in HSVE.

To further address this question, we designed and initiated a prospective, multicenter, randomized, double-blind, placebo-controlled trial (EudraCT-Nr. 2005-003201-81).

\section{Methods}

\section{Study design}

The German trial of Aciclovir and Corticosteroids in Herpes-simplex-virus-Encephalitis (GACHE) was a prospective, multicenter, randomized, double blind, placebo-controlled, parallel group clinical trial in adult patients with recent onset of HSVE to evaluate the effect of early adjuvant corticosteroids (dexamethasone) on morbidity and mortality in the treatment of adult patients with HSVE [1]. Patients were planned to be recruited in 27 Departments of Neurology of academic medical centers in Germany, Austria and The Netherlands; only centers in Germany actually recruited patients. Recruitment rate was based on the incidence of HSVE (2-4 cases/1,000,000). In addition a survey was conducted in all participating centers estimating the anticipated number of cases. All centers expected between two and five yearly cases of HSVE. Full ethical approval for this study was obtained from all responsible Ethics Committees. An independent data safety monitoring board reviewed the study regularly. 


\section{Study patients}

All patients between 18 and 85 years of age with focal neurological signs for not more than 5 days prior to admission to the respective study center were consecutively screened for eligibility and, if considered eligible, invited to participate in the study. Inclusion criteria were age $\geq 18$ to $\leq 85$ years, laboratory-proven HSVE (detection of HSV-DNA in the cerebrospinal fluid (CSF) by polymerase chain reaction (PCR) or a positive CSF HSVspecific antibody-index) and focal neurological signs for not more than 5 days prior to admission. For women of childbearing potential a negative pregnancy testing in urine was necessary [1]. Exclusion criteria are listed in Table 1. Written informed consent was obtained from each subject or from the subject's legal representative or designee before any protocol-specific procedures were performed.

\section{Randomization and blinding}

Study treatment allocation was done in a 1:1 ratio by the method of minimization considering two factors, study center and GCS (dichotomized: $\leq 8,>8$ ). Randomization was performed using the web-based software randomizer (http://www.randomizer.at). The trial was conducted in double-blind fashion with the patient, the treating physician, the observer and all other site personnel as well as the monitor being unaware of the treatment assignment.

Table 1 Exclusion criteria

- History of hypersensitivity to corticosteroids

- Systemic corticosteroid treatment within the last six months or at present time (> 20 mg p.o. or generally intravenous intake)

- Two fixed dilated pupils

- Pre-event score mRS more than two or Barthel Index less than 95

- Pregnancy

- Breast feeding women

- Recent history of active tuberculosis or systemic fungal infection

- Recent head trauma/neurosurgery/peptic ulcer disease

- Life expectancy less than three years

- Other serious illness that confound treatment assessment

- Simultaneous participation in another clinical trial

- Previous participation in another clinical trial in the last 30 days

- Previous participation in this clinical trial

- Women of childbearing potential who are not using a highly effective birth control method

- Acute viral infections other than HSVE (herpes zoster, poliomyelitis, chickenpox)

- Hepatitis B surface Antigen-positive chronic active hepatitis

- Approximately eight weeks before to two weeks after prophylactic vaccination

- Lymphadenitis following Bacille Calmette Guérin vaccination.
Dexamethasone and placebo were provided in identically appearing vials and study kits.

\section{Treatment arms}

All patients were treated with aciclovir intravenously at a dosage of $10 \mathrm{mg} / \mathrm{kg}$ body weight every 8 hours with an infusion time of $1 \mathrm{~h}$, if patients had a normal renal function. In case of reduced creatinine clearance $(<60 \mathrm{ml} /$ min) the aciclovir dosage was adapted. In addition, they received the study medication, either intravenous Dexamethasone at a dosage of $40 \mathrm{mg}$ every $24 \mathrm{~h}$ for 4 days, or placebo that was identical in appearance to the active drug.

All concomitant medications were allowed with exception of actual or long-standing corticosteroid treatment. Gastric protection with an antacid medication was obligatory during the administration of the study medication.

\section{Endpoints}

Functional outcome at 6 months $( \pm 14$ days $)$ after randomization was assessed by the modified Rankin scale (mRS), a seven-point-scale ( 0 to 6 points) with 0 indicating normal neurological function, 6 indicating death and the points in between different grades of disability and dependence. This scale is frequently used in ischemic stroke outcome trials.

The primary endpoint was the mRS dichotomized at $0-2$ vs $3-6$, with $0-2$ regarded as favorable outcome without dependency. A mRS of 3 to 6 was interpreted as unfavorable outcome.

Secondary endpoints included mortality after 6 and 12 months, functional outcome after 6 months measured with the Glasgow outcome scale (GOS), functional outcome after 12 months measured with mRS and GOS, quality of life as measured with the EuroQol 5D instrument (EQ-5D) after 6 and 12 months, neuropsychological testing including Mini-Mental test (MMT), Rey Complex Figure Test, Auditory Verbal Learning and Memory Test (AVLT I and II), Digit Test, Trail-Making Test, Word Fluency Test, Hospital Anxiety and Depression Scale (HADS) after 6 months, cranial MRI findings after 6 months, seizures up to day of discharge or at the latest at day 30, and after 6 and 12 months.

\section{Statistical analysis}

The statistical design was that of a group sequential design with a maximum of three stages, rejection boundaries according to O'Brien and Fleming [19] and a potential sample size adjustment for the last stage [20]. Initial assumptions for sample size calculation were a failure rate of $40 \%$ in the aciclovir monotherapy group and a failure rate of $25 \%$ for the combination therapy of aciclovir plus corticosteroids. For a specified type I error rate of $5 \%$ and equally spaced stages this treatment 
difference can be detected with a power $80 \%$ if a maximum of 52 patients per group and stage are included, i.e. the maximum total sample size is 312 patients (ADDPLAN; Release 3). Assuming a rate of loss to follow-up of $15 \%$ it was planned to include 62 patients per group in each stage which results in a maximum of 372 patients for the entire study. In the second interim analysis a sample size recalculation based on the pooled data of the first and second stage was planned with the option to adapt the sample size to a maximum of 450 patients for the whole study. For more details see [1].

Due to slow recruitment, the study was terminated prematurely before the first interim analysis. Therefore, the final analysis was done according to a fixed sample size design and all results will be interpreted only descriptively.

The primary analysis is based on the full analysis set (FAS) following the intention-to-treat principle. It comprises all patients treated with at least one dose of study medication (aciclovir and dexamethasone/placebo) and analyzed in the group randomized to. As sensitivity analysis, the primary endpoint was additionally analyzed as per protocol (PP). Patients were included into this PP analysis only if all inclusion and exclusion criteria were fulfilled and all medical procedures/visits have been carried out according to the protocol (dexamethasone/placebo over 4 days, if not dead: 6 -month visit within \pm 14 days). In case of randomization through randomization list without entering into the randomization tool afterwards, the patient was excluded from the PP set. The affiliation to the PP set in disputable cases was fixed prior to database closure in a separate document.

For the FAS analysis, missing values for the primary endpoint were imputed using the last observationcarried-forward approach. Patients who died between randomization and the 6 months visit were evaluated with $\mathrm{mRS}=6$ at the 6 months visit. In addition, worst case and best case scenarios were evaluated based on the FAS meaning that in both.

treatment groups the worst $(\mathrm{mRS}>2)$ or best $(\mathrm{mRS} \leq$ 2) outcome was assumed in case of missing values.

Patients who died between randomization and the 12 months visit were evaluated with $\mathrm{mRS}=6$ at the 12 months visit. HADS defines two subscales, the anxiety score and the depression score. Each score was calculated adding up the values given for seven items. In case of one missing value within a subscale, this value was imputed using the mean value of the six other items. If more than one item was missing within a subscale, no imputation was done. The subscales were categorized into negative $(0-7)$, neutral $(8-10)$ and positive $(\geq 11)$ and tabulated by treatment. For further secondary endpoints no imputation was done. For the PP set no missing values were imputed.
All secondary endpoints were analyzed based on the FAS and the PP set. In case of categorical variables, $p$ values correspond to the $\mathrm{Chi}^{2}$-test, in case of continuous variables, $\mathrm{p}$-values are given for the nonparametric U-test. Mortality was evaluated through Kaplan Meier curves and $\log$ rank tests were performed.

Due to the small number of randomized patients and the partly high amount of missing data (e.g. for GCS Scale at baseline) no further analyses such as regression analyses were conducted.

The main safety parameter is death which was analyzed as secondary endpoint. Additionally to that, death was analyzed in the same manner based on the safety analysis set which contains all patients who were treated at least for 1 day (aciclovir dexamethasone/placebo) and patients were categorized into groups as treated.

All analyses have been done using validated $\mathrm{SAS}^{\circ}$ Version 9.1 run on a Linux system. Stacked bar graphs for mRS have been created using R Version 3.5.1.

\section{Results \\ Demographics and baseline characteristics}

One thousand one hundred twenty-nine patients were screened by 27 centers between November 2007 and December 2012. After exclusion of 1087 patients, finally 41 patients were randomized to dexamethasone plus aciclo$\operatorname{vir}(N=21)$ (dexamethasone group) or to placebo plus aciclovir) $(N=20)$ (placebo group) (Fig. 1). A CONSORT flow chart is presented in Fig. 1. We had to exclude 3 patients from FAS after randomization because of informed consent withdrawal $(N=2)$ and screening failure $(N=1)$. Both treatment groups were characterized using descriptive methods based on the FAS and PP set. In this paper we describe the FAS group, for further details of the PP set we refer to the online published data set (see electronical Additional file 1). Table 2 summarizes the demographics for the patients in the FAS which consist of 19 patients in each group. No severe group differences were present at baseline. Patients in the Dexamethasone group were on average 3 years older and had more often neurological signs at onset $(78.9 \%$ vs. $63.2 \%$ ). The pre-encephalitis $\mathrm{mRS}$ was also minimally higher in the Dexamethasone group (mRS 0: Placebo $n=17$, Dexamethasone $n=14 ; \mathrm{mRS} \geq 1$ : Placebo $n=2$, Dexamethasone $n=5$ ).

\section{Primary endpoint}

No differences in the dichotomized mRS outcome scale were found between the Placebo and Dexamethasone groups. In both groups, 12 patients had a $\mathrm{mRS} \leq 2$, seven patients had $>2(p=1.0)$, respectively. This was confirmed in the sensitivity analyses. Table 3 and Fig. 2 show the mRS at 6-month visit, for both study groups, placebo and dexamethasone. 


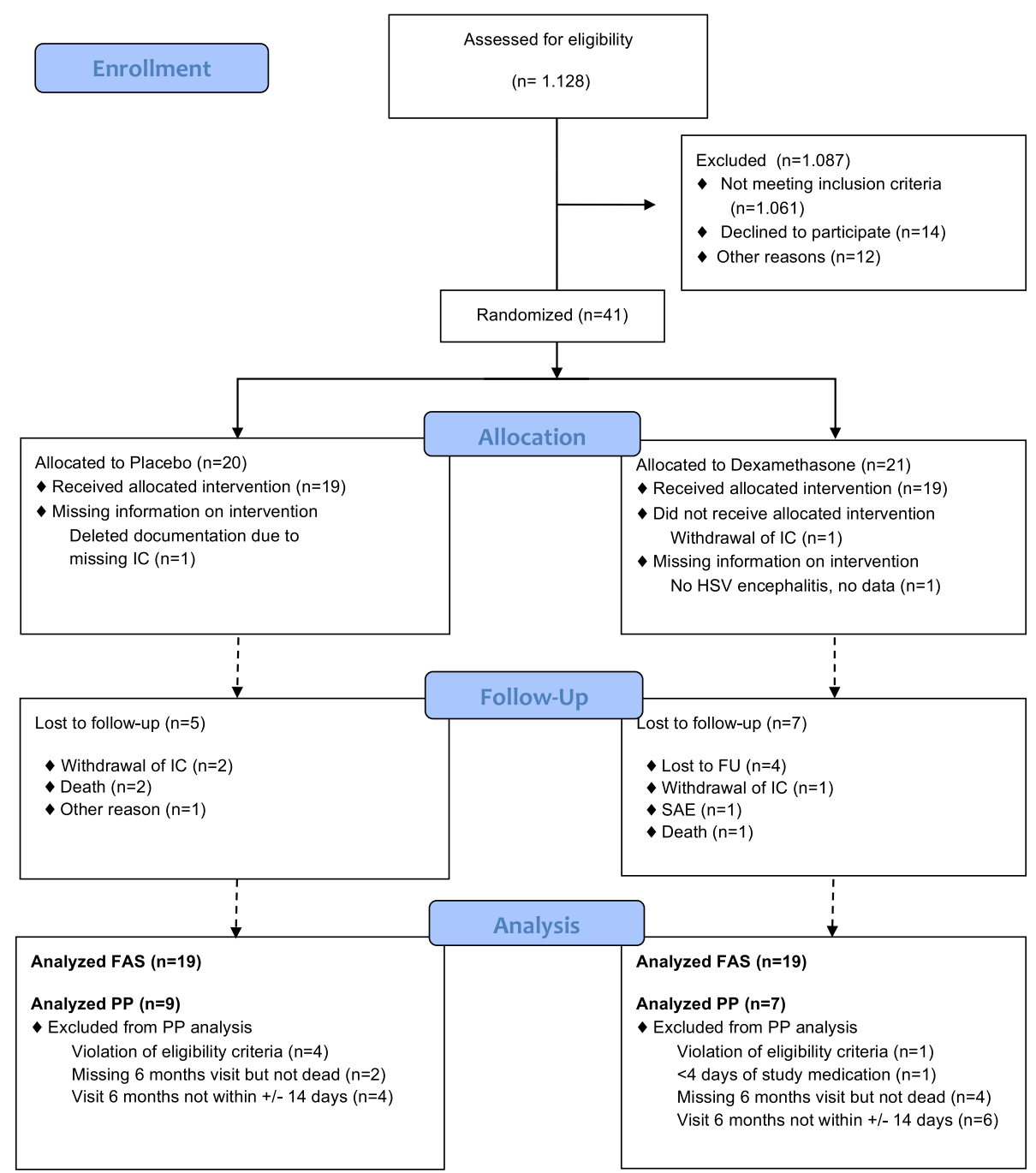

Fig. 1 Flow chart of enrolled patients. Shows the flow chart or patient enrollment. We have screened 1.128 Patients, after exclusion of 1.087 patients, finally 41 patients were enrolled in the trial.

Table 2 Baseline characteristic of the patients in the FAS

\begin{tabular}{|c|c|c|c|}
\hline & $\begin{array}{l}\text { Placebo } \\
N=19\end{array}$ & $\begin{array}{l}\text { Dexamethasone } \\
N=19\end{array}$ & $\begin{array}{l}\text { Total } \\
N=38\end{array}$ \\
\hline \multicolumn{4}{|l|}{ Gender } \\
\hline male & $10(52.6 \%)$ & $11(57.9 \%)$ & $21(55.3 \%)$ \\
\hline female & $9(47.4 \%)$ & $8(42.1 \%)$ & $17(44.7 \%)$ \\
\hline \multicolumn{4}{|l|}{ Age } \\
\hline Mean +/- SD & $58.6+/-15.0$ & $61.6+/-12.1$ & $60.1+/-13.6$ \\
\hline \multicolumn{4}{|c|}{ Focal neurological signs } \\
\hline yes & $12(63.2 \%)$ & 15 (78.9\%) & $27(71.1 \%)$ \\
\hline \multicolumn{4}{|c|}{ Seizures within last 5 days } \\
\hline yes & $11(57.9)$ & $11(57.9 \%)$ & $22(57.9 \%)$ \\
\hline \multicolumn{4}{|l|}{ Result of PCR } \\
\hline positive & $19(100.0 \%)$ & 19 (100.0\%) & $38(100.0 \%)$ \\
\hline
\end{tabular}

\section{Secondary endpoints}

Results for secondary endpoints are given in Tables 3 and 4. Overall, 3 patients died within 12 months. In the dexamethasone group, one patient died within 6 months. In the placebo group 2 patients died within 12 months. No differences in the mortality rates could be detected (Table $3)$. Neither after six $(p=0.266)$, nor after 12 months ( $p=$ 0.681). Similarly, no relevant differences in the functional outcome after six and 12 months were found. The GOS after 6 months $(p=0.46)$ and 12 months $(p=0.773)$ turned out to be similar in both groups. Furthermore, the quality of life was not different between the groups after 6 months [EQ-5D-Index $(p=0.243)$ and EQ-5D-VAS $(p=$ $0.184)$ ] and 12 months [EQ-5D-Index $(p=0.812)$ and EQ$5 \mathrm{D}-\mathrm{VAS}(p=0.296)]$ as well as the modified ranking scale after 12 months $(p=0.897)$. No relevant differences were found in all neuropsychological tests after 6 months (see 
Table 3 Results for the FAS after 6 and 12 months (mRS, mortality)

\begin{tabular}{|c|c|c|c|c|}
\hline & Placebo & Dexamethasone & Total & $p$-value \\
\hline & $N=19$ & $N=19$ & $N=38$ & \\
\hline Dichotomiz & $\mathrm{mRS}$ at $6 \mathrm{~m}$ & ths & & \\
\hline$<=2$ & $12(63.2 \%)$ & 12 (63.2\%) & $24(63.2 \%)$ & 1.0000 \\
\hline$>2$ & $7(36.8 \%)$ & 7 (36.8\%) & $14(36.8 \%)$ & \\
\hline Mortality at & months & & & \\
\hline Alive & $18(100 \%)$ & $14(93.3 \%)$ & 32 (97.0\%) & 0.2660 \\
\hline Dead & $0(0) \%)$ & $1(6.7 \%)$ & $1(3.1 \%)$ & \\
\hline Missing & 1 & 4 & 5 & \\
\hline Dichotomiz & $\mathrm{mRS}$ at 12 & inths & & \\
\hline$<=2$ & $9(56.3 \%)$ & $7(53,8 \%)$ & $16(55.2 \%)$ & 0.8970 \\
\hline$>2$ & 7 (43.8\%) & $6(46.2 \%)$ & $13(44.8 \%)$ & \\
\hline Missing & 3 & 6 & 9 & \\
\hline Mortality at & 2 months & & & \\
\hline Alive & $13(86.7 \%)$ & $11(91.7 \%)$ & $24(88.9 \%)$ & 0.6812 \\
\hline Dead & $2(13.3 \%)$ & $1(8.3 \%)$ & $3(11.1 \%)$ & \\
\hline Missing & 4 & 7 & 11 & \\
\hline
\end{tabular}

Table 4). Seizure activity was similar in both groups up to day of discharge or at the latest at day $30(p=0.632)$, and after 6 months $(p=0.713)$ and 12 months $(p=0.271)$ as well.

\section{Discussion}

We designed and initiated GACHE as a prospective multicentre, multinational, randomized, double-blind, placebo-controlled trial. Due to slow recruitment, the study was terminated prematurely. All centers recruited less patients than initially stated in the evaluation. Further studies should take into account the possibly overestimated incidence of the disease. The study was massively underpowered and its primary and secondary endpoints can only be interpreted with caution. Although there were no differences in mortality and the dichotomized mRS at 6 months between both groups, treatment with adjuvant dexamethasone did not have unexpected side effects which harmed patients in our study. Specifically, 21 patients suffering from HSVE were treated with combination of dexamethasone and aciclovir without serious side effects.

HSVE is a life threatening infectious disease of the central nervous system. Untreated HSVE mortality exceeds $70 \%$ and remains at $20 \%$ with antiviral treatment. Aciclovir, a synthetic guanosine analogue, is used for treating herpes simplex virus infection. Intravenous

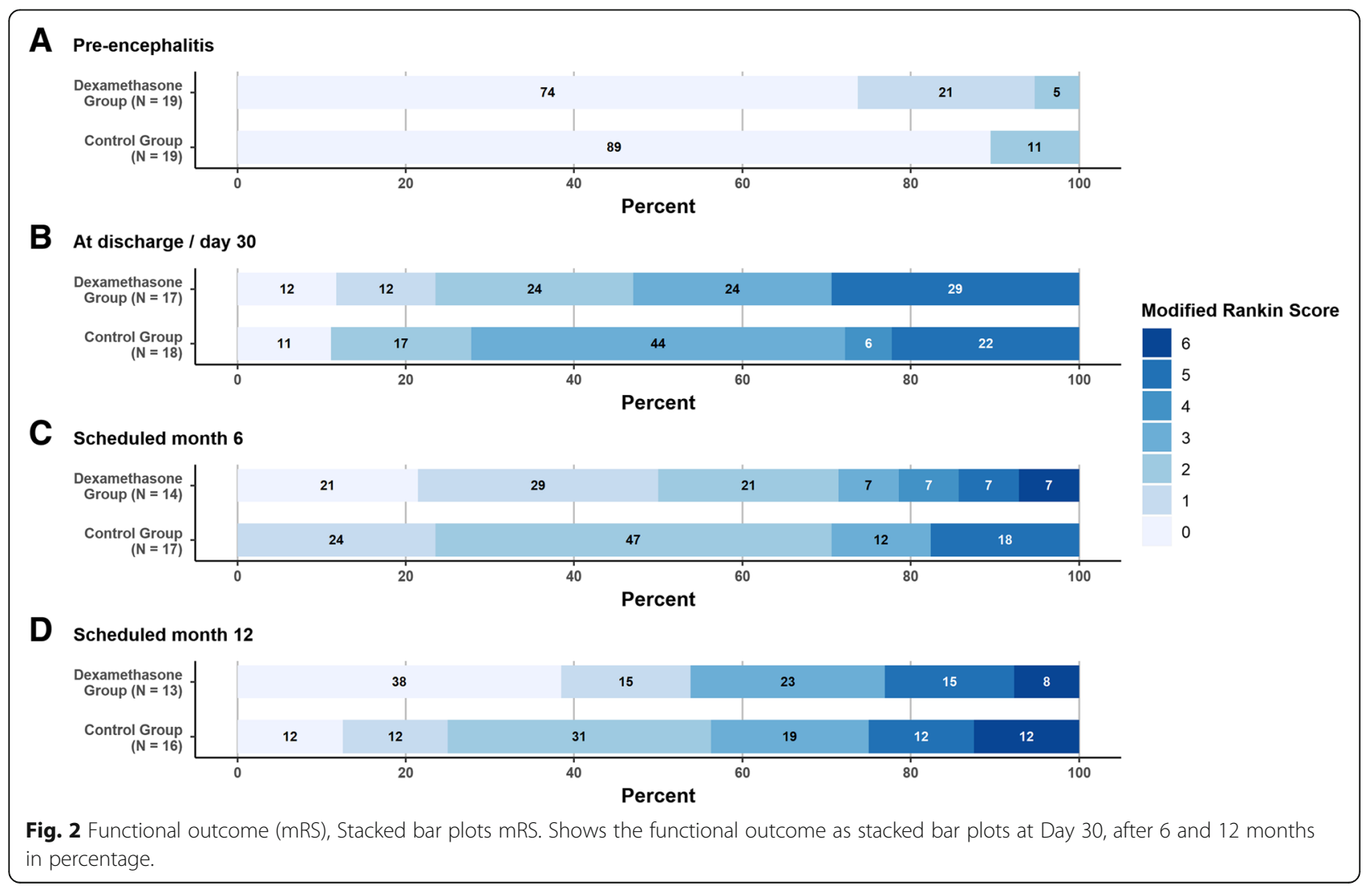


Table 4 Results for the FAS after 6 months (neuropsychology)

\begin{tabular}{|c|c|c|c|c|}
\hline & Placebo & Dexamethasone & Total & $p$-value \\
\hline & Mean +/- SD & Mean +/-SD & Mean $+/-$ SD & \\
\hline MMT (total score) & $26,7+/-2,6$ & $26,7+/-2,6$ & $26,6+/-3,1$ & 0,775 \\
\hline Rey Complex Figure Test (sum of copy/immediate/recall) & $43,8+/-11,3$ & $41,1+/-9,9$ & $42,6+/-10,5$ & 0,602 \\
\hline \multicolumn{5}{|l|}{ AVLT I and II } \\
\hline Learning Trial & $42,1+/-16,9$ & $30,6+/-12,3$ & $42,6+/-10,5$ & 0,103 \\
\hline Interference trial & $7,4+/-5,6$ & $4,2+/-4,2$ & $5,8+/-5,1$ & 0,163 \\
\hline Delayed recall & $6,1+/-4,7$ & $3,8+/-4,3$ & $5,0+/-4,5$ & 0,244 \\
\hline \multicolumn{5}{|l|}{ Digit Span } \\
\hline forward Total & $5,8+/-2,4$ & $8,0+/-2,3$ & $6,9+/-2,5$ & 0,051 \\
\hline backward Total & $5,2+/-2,0$ & $5,6+/-1,9$ & $5,4+/-1,9$ & 0,585 \\
\hline \multicolumn{5}{|l|}{ Trail Making Test } \\
\hline Time Test A (sec.) & $45,5+/-45,3$ & $60,0+/-40,4$ & $52,7+/-42,7$ & 0,101 \\
\hline Time Test B (sec.) & $155,3+/-198,4$ & $160,0+/-95,0$ & $157,8+/-150,2$ & 0,314 \\
\hline Word Fluency (Total) & $32,5+/-10,6$ & $28,8+/-10,4$ & $30,7+/-10,5$ & 0,572 \\
\hline \multicolumn{5}{|l|}{ HADS-D } \\
\hline Anxiety-Score & $7,6+/-4,5$ & $7,4+/-4,0$ & $7,5+/-4,2$ & 0,572 \\
\hline Depression-Score & $7,5+/-5,2$ & $6,8+/-4,5$ & $7,2+/-4,7$ & 0,572 \\
\hline
\end{tabular}

aciclovir provides modest bioavailability of $15-30 \%$ and is the first line treatment for HSVE [2-4]. One limitation of HSVE therapy is failure of early initiation of aciclovir therapy. Several studies indicate that in many cases, there is an unacceptable delay between clinical presentation and antiviral drug therapy. This delay is related to a poorer clinical outcome. The significant morbidity rates in HSVE warrant the active investigation of improved therapeutic approaches $[2,3,5]$.

After introduction of antiviral therapy, reports indicated progressive tissue damage in later phases of the disease, also demonstrated in animal studies [6, 7]. Autoimmune mechanisms were proposed as a possible cause $[1,7]$. Recently also immune-mediated antibody-driven mechanisms (e.g. anti NMDA-R-IgG, anti-N-typeVGCC) in a subgroup of patients following HSVE were described [21, 22].

In the pre-aciclovir era, corticosteroids were used in HSVE, because of their anti-inflammatory potency. Perceived but not proven corticosteroids effects were attributed to its suppressive mechanism concerning cerebral edema and local inflammation $[2,14,15]$.

Currently the use of steroids in HSVE is an off-label treatment. A few case studies have concluded that patients treated with additional dexamethasone may have a better long term outcome $[2,16,17]$. There have been no large cohort studies or prospective trials indicating that the use of adjunctive steroids in HSVE improves long term outcome and inhibits ongoing tissue damage. GACHE is the first prospective multicenter, multinational, randomized, double blind trial studying the effect of adjuvant dexamethasone versus placebo on top of standard aciclovir treatment in adult patients, but was terminated due to slow recruitment. However, a study in UK analyzes additional dexamethasone in HSVE and is still on-going [23]. A prospective registry for patients receiving dexamethasone adjunct therapy may also help to further assess the safety of this treatment approach.

\section{Conclusion}

GACHE studied the effect of adjuvant dexamethasone versus placebo on top of standard aciclovir treatment in adult patients aged 18 up to 85 years with proven HSVE in German academic centers of Neurology in a randomized and double blind fashion. GACHE being prematurely terminated demonstrated problems encountered performing randomized, placebo-controlled trials in life threatening neurological diseases. Unfortunately, the small number of study participants does not allow firm conclusions. Despite all this, GACHE shows the difficulties in patient recruitment for such a rare life-threatening disease. Based upon our trial results the use of adjuvant steroids in addition to antiviral treatment remains experimental and is at the decision of the individual treating physician.

\section{Additional file}

Additional file 1: Statistic report. (PDF $4057 \mathrm{~kb}$ )

Abbreviations

AVLT: Auditory Verbal Learning and Memory Test; CSF: Cerebrospinal fluid; EQ-5D: Quality of life as measured with the EuroQol 5D instrument; FAS: Full 
analysis set; GACHE: German trial of aciclovir and corticosteroids in Herpes simplex virus encephalitis; GCS: Glasgow coma scale score; GOS: Glasgow outcome scale score; HADS: Hospital anxiety and depression scale; HSVE: Herpes-simplex-virus-encephalitis; MMT: Mini-Mental Test; MRI: Magnetic resonance imaging; mRS: modified Ranking Scale; PCR: Polymerase chain reaction; PP: Per protocol

\section{Acknowledgements}

We would like to thank Gholamreza Darai for decades of support. We would also like to thank Jan de Gans, Diederik van de Beek, Ulrich Mansmann, Nobert Victor, the former Director of the Department of Biometrics, University of Heidelberg, and all the project managers in between, especially Dr. Lilian Faber, Dr. Christoph Mohs who were critical during the audit inspections and greatly helped organizing the Trail Master File.

\section{Authors'contributions}

MLU, JC and CE wrote and revised the manuscript. MLU and JC contributed equally to the manuscript.

All authors read and approved the final manuscript for submission.

\section{Funding}

GACHE was funded by the German federal ministry of education and research, Bundesministerium für Bildung und Forschung.

\section{Availability of data and materials}

The authors confirm that the data supporting the findings of this study are available within the article and its Additional file 1.

\section{Ethics approval and consent to participate}

Approval by the ethics committee of the University of Heidelberg, AFmu106/2006, was obtained. All subjects gave written informed consent.

\section{Consent for publication}

Not applicable.

\section{Competing interests}

The authors declare that they have no competing interests.

\section{Author details}

${ }^{1}$ Department of Neurology, Krankenhaus Nordwest, Frankfurt, Germany. ${ }^{2}$ Department of Neurology, University of Heidelberg, Heidelberg, Germany. ${ }^{3}$ Department of Neuroradiology, Krankenhaus Nordwest, Frankfurt, Germany. ${ }^{4}$ Institute of Medical Biometry and Informatics, University of Heidelberg, Heidelberg, Germany. ${ }^{5}$ Department of Neurology, Charité Universitätsmedizin Berlin, Berlin, Germany. ${ }^{6}$ Department of Neurology, Vivantes Auguste-Viktoria-Klinikum, Berlin, Germany. ${ }^{7}$ Department of Neurology, Vivantes Klinikum im Friedrichshain, Berlin, Germany. ${ }^{8}$ Department of Neurology, Klinikum Darmstadt, Darmstadt, Germany. ${ }^{9}$ Department of Neurology, Universitätsklinikum Frankfurt, Frankfurt, Germany. ${ }^{10}$ Department of Neurology, Universitätsklinikum Hamburg-Eppendorf, Hamburg, Germany. ${ }^{11}$ Department of Neurology, Klinikum Kassel, Kassel, Germany. ${ }^{12}$ Department of Neurology, Universitätsklinikum Leipzig, Leipzig, Germany. ${ }^{13}$ Department of Neurology, Klinikum der Stadt Ludwigshafen am Rhein, Lugwigshafen, Germany. ${ }^{14}$ Department of Neurology, Klinikum der Ludwig-MaximiliansUniversität München, Großhadern, Germany. ${ }^{15}$ Department of Neurology, Universitätsklinikum Regensburg, Regensburg, Germany.

${ }^{16}$ Koordinierungszentrum für Klinische Studien (KKS), University of Heidelberg, Heidelberg, Germany. ${ }^{17}$ Department of Neurology, Klinikum Fulda, Fulda, Germany. ${ }^{18}$ Praxis Dr. Meyer \& Prof. Claus, Bensheim, Germany. ${ }^{19}$ Department of Neurology, Zentralklinik Bad Berka, Bad Berka, Germany. ${ }^{20}$ Department of Pharmacy Heidelberg, Heidelberg University Hospital, Heidelberg, Germany. ${ }^{21}$ Department of Neurology, University of Freiburg, Freiburg, Germany. ${ }^{22}$ Universitätsklinikum Carl Gustav Carus, Dresden, Germany. ${ }^{23}$ Division of Brain Injury Outcomes, John Hopkins University, Baltimore, MD, USA.
Received: 25 April 2019 Accepted: 7 June 2019

Published online: 12 September 2019

\section{References}

1. Martinez-Torres, F., Menon, S., Pritsch, M., Victor, N., Jenetzky, E., Jensen, K., Schielke, E., Schmutzhard, E., de Gans, J., Chung, C. H., Lunz, S., Hacke, W., Meyding-Lamadé, U., \& and The GACHE Investigators. (2008). Protocol for German trial of Aciclovir and corticosteroids in herpes-simplex-virusencephalits (GACHE): A multicentre, multinational, randomized, doubleblind, placebo-controlled German, Austrian and Dutch trial [ISRCTN45122933]. BMC Neurology, 8, 40.

2. Bradshaw, M. J., \& Venkatesan, A. (2016). Herpes-simplex-Viorus-1 encephalitis in adults: Patophysiology, diagnosis, and management. Neurotherapeutics, 13, 493-508.

3. Kimberlin, D. W., \& Withley, R. J. (2007). Chapter 64: Antiviral therapy of HSV1 and HSV-2. In Arvin A, Campadelli-Fiume G, Mocarski E, et al., editors. Human herpesviruses: Biology, therapy and Immunoprophylaxis. Cambridge: Cambridge University Press; 2007.

4. Razonable, R. (2001). Antiviral drugs for viruses other than human immunodeficiency virus. Mayo Clinic Proceedings, 86, 1009-1026.

5. Raschilas, F., Wolff, M., Delatour, F., Chaffaut, C., de Broucker, T., Chevret, S., Lebon, P., Canton, P., Rozenberg, F., \& For the French Herpes Simplex Encephalits Study Group. (2002). Outcome of and prognostic factors for herpes simplex Encephalits in adult patients: Results of a multicentre study. Clinical Infectious Diseases, 35, 254-260.

6. Meyding-Lamadé, U., Lamadé, W., Hess, K., Degen, O., Sartor, K., Oberlinner, C. H., \& Hacke, W. (1999). Herpes simplex virus encephalitis: Chronic progressive cerebral MRI changes in patients despite good clinical recovery. Clinical Infectious Diseases, 28, 148-149.

7. Meyding-Lamadé, U., Lamadé, W., Kehm, R., Heß, T., Fäth, A., Wildemann, B., Hass, J., \& Hacke, W. (1999). Herpes simplex virus encephalitis: Chronic progressive cerebral MRI changes despite good clinical recovery and low viral load. An experimental mouse study. European Journal of Neurology, 6, 531-538.

8. Meyding-Lamadé, U., Seyfer, S., Haas, J., Dvorak, F., Kehm, R., Lamadé, W. Hacke, W., \& Wildemann, B. (2002). Experimental herpes simplex virus encephalitis: Inhibition of the expression of inducible nitric oxide synthase in mouse brain tissue. Neuroscience Letters, 318, 21-24.

9. Martinez-Torres, F. J., Wagner, S., Hass, J., Kehm, R., Sellner, J., Hacke, W., \& Meyding-Lamadé, U. (2005). Increases presence of matrix metalloproteinases 2 and 9 in short- and long-term experimental herpes simplex virus encephalitis. Neuroscience Letters, 374, 274-278.

10. Sellner, J., Dvorak, F., Zhou, Y., Haas, J., Kehm, R., Wildemann, B., \& MeydingLamadé, U. (2005). Acute and long-term alteration of chemokine mRNA expression after anti-viral and anti-inflammatory treatment in herpes simplex virus encephalitis. Neuroscience Letters, 374, 197-202.

11. Wildemann, B., Ehrhart, K., Storch-Hagenlocher, B., Meyding-Lamadé, U., Steinvorth, S., Hacke, W., \& Haas, J. (1997). Quantitation of herpes simplex virus type 1 DNA in cells of cerebrospinal fluid of patients with herpes simplex virus encephalitis. Neurology, 48, 1341-1346.

12. Meyding-Lamadé, U., Oberlinner, C., Rau, P. R., Seyfer, S., Heiland, S., Sellner, J., Wildemann, B., \& Lamadé, W. (2003). Experimental herpes simplex virus encephalitis: A combination therapy of aciclovir and glucocorticoids reduces long-term magnetic resonance imaging abnormalities. Journal of Neurovirology, 9, 118-125.

13. Thompson, K. A., Blessing, W. W., \& Wesselingh, S. L. (2000). Herpes simplex replication and dissemination is not increased by corticosteroid treatment in a rat model of focal herpes encephalitis. Journal of Neurovirology, 6, 25-32.

14. Upton, A. R., Foster, J. B., \& Barwick, D. D. (1971). Dexamethasone treatment in herpes simplex encephalitis. Lancet, 1, 861.

15. Habel, A. H., \& Brown, J. K. (1972). Dexamethasone in herpes-simplex encephalitis. Lancet, 1, 695

16. Fitch, M. T., \& van de Beek, D. (2008). Drug insight: Steroids in CNS infectious diseases - New indications for an old therapy. Nature Clinical Practice Neurology, 4, 97-104.

17. Kamei, S., Sekizawa, T., Shiota, H., Mizutani, T., Itoyama, Y., Takasu, T., Morishima, T., \& Hirayanagi, K. (2005). Evaluation of combination therapy using aciclovir and corticosteroid in adult patients with herpes simplex virus encephalitis. Journal of Neurology, Neurosurgery, and Psychiatry, 76, 1544-1549. 
18. Lizarraga, K. J., Alexandre, L. C., Ramos-Estebanez, C., \& Merenda, A. (2013). Are steroids a beneficial adjunctive therapy in the immunosuppressed patient with herpes simplex virus encephalitis? Case Reports in Neurology, 5, $52-55$.

19. PC, O.'. B., \& Fleming, T. R. (1979). A multiple testing procedure for clinical trials. Biometrics, 35, 549-556.

20. Müller, H. H., \& Schäfer, H. (2004). A general statistic principle for changing a design any time during the course of a trial. Statistics in Medicine, 23, 24972508.

21. Pruss, H., Finke, C., Holtje, M., et al. (2012). N-methyl-D-aspartate receptor antibodies in herpes simplex encephalitis. Annals of Neurology, 72, 902-911.

22. Bradshaw, M. J., Pawate, S., Lennon, V. A., Bloch, K. C., \& Brown, K. M. (2015). Herpes simplex virus 1 encephalitis associated with voltagegated calcium channel autoimmunity. Neurology, 85, 2176-2177.

23. DexEncaph: A study of dexamethasone in adults with herpes simplex virus (HSV) encephalitis. http://www.dexenceph.org.uk/

\section{Publisher's Note}

Springer Nature remains neutral with regard to jurisdictional claims in published maps and institutional affiliations.

Ready to submit your research? Choose BMC and benefit from:

- fast, convenient online submission

- thorough peer review by experienced researchers in your field

- rapid publication on acceptance

- support for research data, including large and complex data types

- gold Open Access which fosters wider collaboration and increased citations

- maximum visibility for your research: over $100 \mathrm{M}$ website views per year

At BMC, research is always in progress.

Learn more biomedcentral.com/submissions 